\title{
PREFERENCE FOR DRY FISH AMONG ADOLESCENT GIRLS
}

\author{
M. Sai Leela ${ }^{1}$, (D) V. Sony $^{1}$ and Singh Kumari Dipali ${ }^{1}$ \\ ${ }^{1}$ Department Of Home Science, St.Joseph's College For Women, Visakhapatnam, Andhra Pradesh, India
}

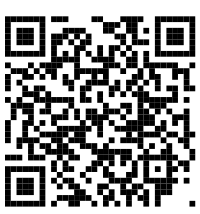

Received 4 July 2021

Accepted 22 July 2021

Published 31 July 2021

Corresponding Author

M. Sai Leela, slmodem@gmail.com

DOI $10.29121 /$

granthaalayah.v9.i7.2021.4138

Funding: This research received no specific grant from any funding agency in the public, commercial, or not-for-profit sectors.

Copyright: (C) 2021 The Author(s). This is an open access article distributed under the terms of the Creative Commons Attribution License, which permits unrestricted use, distribution, and reproduction in any medium, provided the original author and source are credited.

OPEN ACCESS

\section{ABSTRACT}

Dry fish consumption is traditionally part of the diets in Andhra Pradesh. The present study aims at understanding the current trend in dry fish consumption in the context of urbanization. The study comprised of 490 college going adolescent girls (non-vegetarians) from Andhra Pradesh, India. The dietary data was elicited by the Food frequency method. The study points that dry fish is preferred by adolescents in both urban and rural areas of Andhra Pradesh.

Keywords: Dried Fish, Consumption, Nutrition, Food Security, Visakhapatnam

\section{INTRODUCTION}

Early Indians ate food that was easily available from nature. Fruits, wild berries, meat, fish, etc. were the main food items of the nomadic dwellers. With the advent of civilization, people settled and started to do farming. This led to the discovery of food crops, pulses, etc. Food in ancient India was cultivated in the fertile river valleys. Rice was their staple food that was eaten with cooked lentils, vegetables and meat. Fish and seafood came to be eaten along the rivers "The Indian History, From Stone Age To Modern India" (2021).

Since fresh foods such as the fruits, vegetables meats, fish, sea foods were highly prone to spoilage Manay and Swamy (2021), man had to resort to food preservation to prevent food wastage primarily Wilson (1991). According to Nummer (2002) evidence shows that Middle East and oriental cultures actively dried foods as early as 12,000 B.C. in the hot sun. This process helped in storing food for future needs and in off season as well. That is how the dried fish as a commodity has emerged in the diets of people world over.

Anand (2020), reported that dried fish is much loved alternative to fresh fish across the country. Dried fish segment constitutes to $20 \%$ of the total fish production in India Assocham (2016). Das et al. (2013), reported great demand for dried fish products and as an important source of protein. There is also a mention of the flourishing dry fish trade in Visakhapatnam district in Andhra Pradesh, about 50km., away from the popular port city, Visakhapatnam. 
Nayak (2021), in a food blog enumerated the numerous advantages of consuming dry fish on human health. Siddhnath et al. (2020) in a review paper on contribution of dry fish towards food and nutritional security have enumerated its highquality nutrients such as proteins, eicosapentaenoic acid (EPA) and docosahexaenoic acid (DHA) and essential nutrients such as iodine, zinc, copper, selenium, and calcium. Shashikanth et al. (2020), detailed the consumers' preference for fish in their study of households in Karnataka.

Sajeev et al. (2020) reported decline in dry fish consumption in Kerala while Immaculate et al. (2013) mention that the demand for dry fish is more in locations like hilly areas and non-coastal areas, where fresh fish availability is minimal and expensive. Similarly, Das et al. (2013) also reported higher demand for dry fish during seasonal fishing ban in region of Visakhapatnam, Andhra Pradesh. S. Singh (2017) explained the details of fishing ban for marine health. According to Anand (2020), dry fish was much sought after during the lockdown in view of the Corona pandemic, as the fresh fish availability was hampered. Madhavi and Kusuma (2015), stated in their study of the households in Andhra Pradesh, that while dried fish is liked, it has not been given due importance because of issues like strong and unpleasant odour, poor quality etc.

\section{MATERIALS AND METHODS}

The present study aims at understanding the adolescents' interests in dry fish consumption. The data on dry fish consumption in their households was elicited based on a short survey. The study comprised of 490 college going adolescent girls from Andhra Pradesh, India. and who were non-vegetarians. The dietary data was elicited by the Food frequency method. The data was analysed using Microsoft excel. The sample was categorized region wise as urban and rural, based on the native place for understanding the differentials in food consumption pattern. The percentages were calculated to compare the consumption pattern among groups. The Chi square test of significance was applied.

\section{RESULTS AND DISCUSSION}

The results obtained through analysis are presented as follows.The dry fish consumption pattern of the study group is presented in Fig.1. It is observed from this chart, that $63 \%$ did not prefer to eat dry fish, while $37 \%$ consume it. The frequency of consumption of dry fish is weekly (13\%) and monthly (24\%). None consumed daily. 


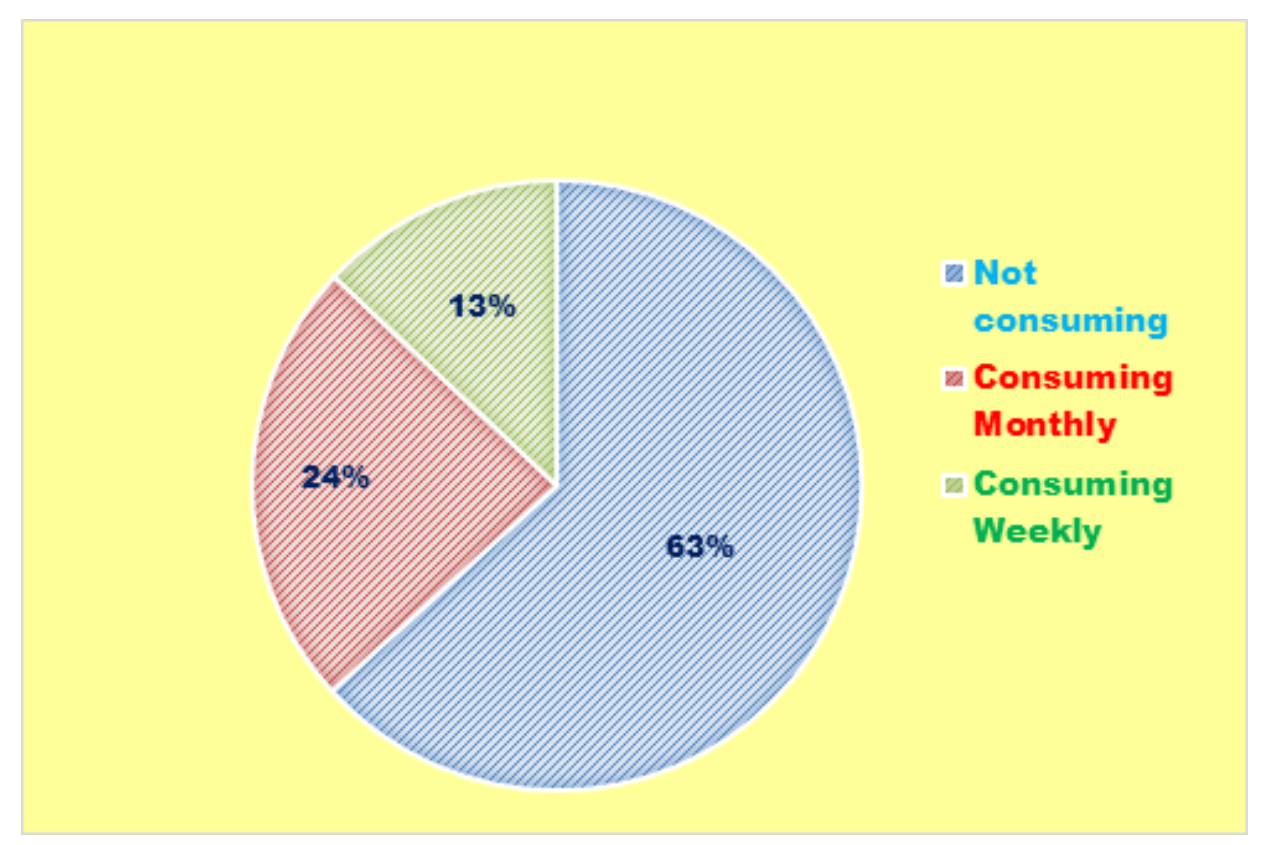

Figure 1 Dry Fish Consumption pattern among adolescents

The comparison of dry fish consumption among adolescents of urban and rural Andhra Pradesh can be observed from Figure 2 .

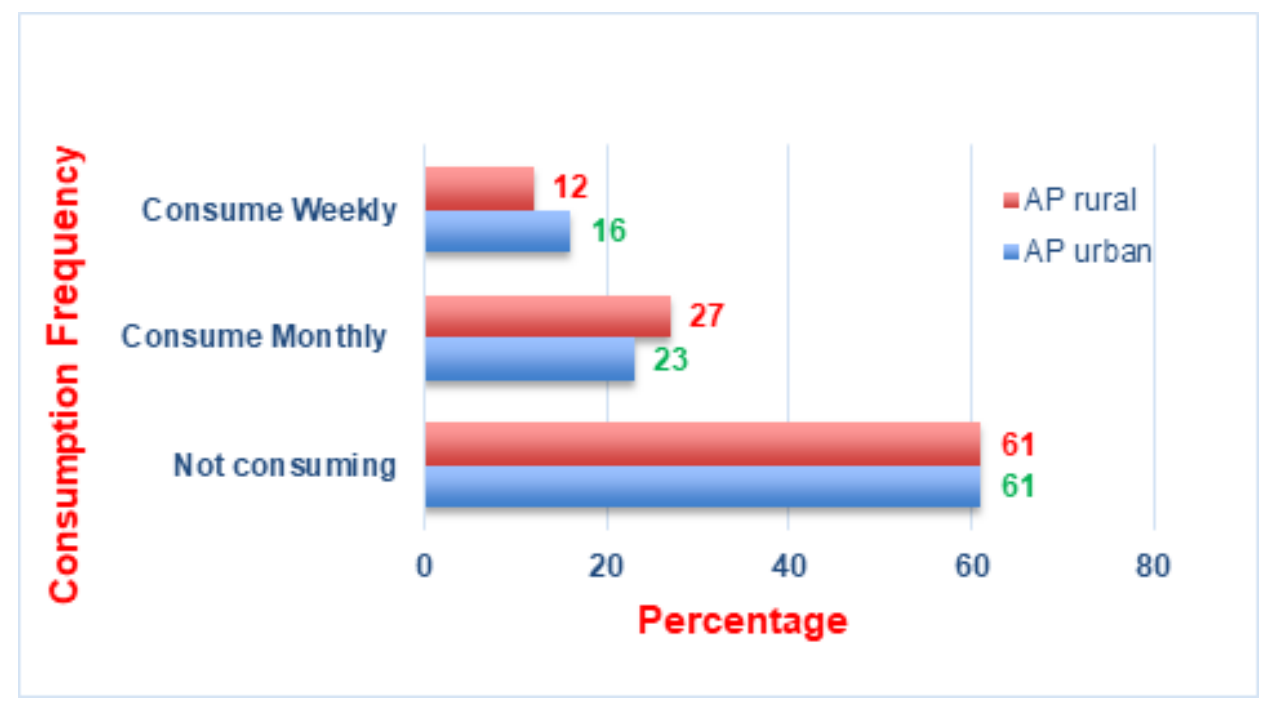

Figure 2 Comparison of Dry fish consumption (\%) in urban and rural Andhra Pradesh

It is interesting to note that $61 \%$ of respondents in both urban and rural do not consume dry fish. Among the other 39\%, the monthly consumption rather than 
weekly was noticed. The difference in frequency of consumption is more marked in rural group. However, the difference between the groups is not statistically significant (Chi square).

The results of the present study compare well with the results of another study from Andhra Pradesh with regard to the weekly and monthly pattern of consumption Madhavi and Kusuma (2015). In order to understand the phenomenon of frequency and preference for dry fish, its' consumption was compared with the consumption of other non-vegetarian (fleshy) foods and is presented in Figure 3 .

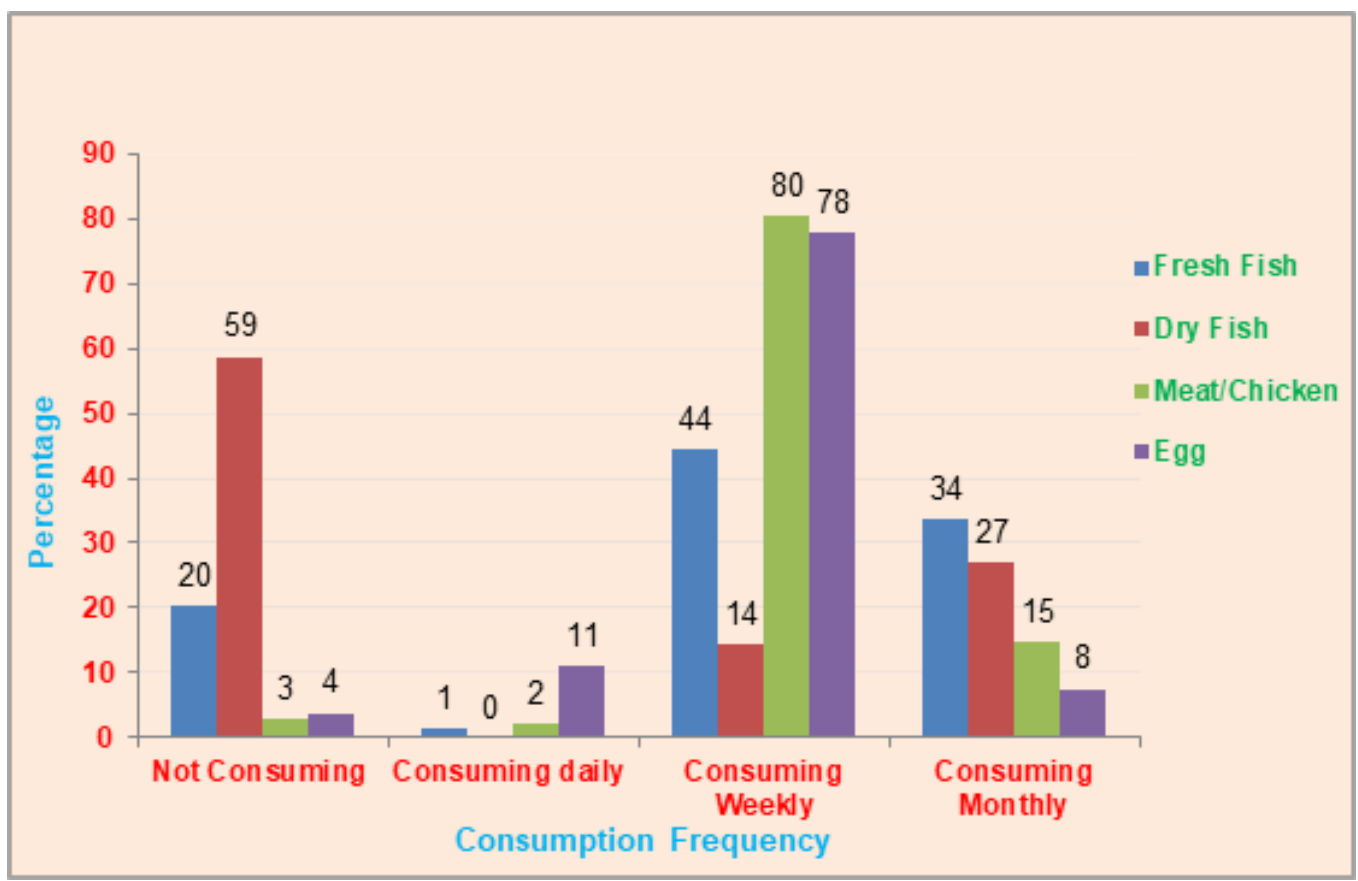

Figure 3 Dry fish consumption in relation to other non-vegetarian foods

The results show a very interesting trend. Among the foods not eaten frequently, dry fish is highest at $50 \%$ followed by fresh fish (20\%). The frequency of not eating meat, chicken and egg is only $3-4 \%$. So, there is a clear tendency of least preference for fish per se, as compared to the other non-vegetarian foods. The preference for fresh fish is higher than dry fish, among the two forms of fish. Egg is preferred to be consumed daily by $11 \%$ of the respondents while meat and chicken were preferred weekly (80\%), and the fish, both fresh and dry was preferred monthly only.

From the foregoing results, it is quite clear that dry fish is preferred by adolescents across Andhra Pradesh, although in small percent. However, the increased availability (especially in urban areas), affordability and the ease of preparation of other non -vegetarian foods like mutton, chicken and egg has made the dry fish a lesser popular food and hence a low preference is observed. The modernization, urban lifestyle, improved disposable income and the accessibility and availability of diversified foods would have impacted the dry fish consumption pattern in Andhra Pradesh. The UN- 
FAO data on India meat production K. Singh (2020), showed a steady rise from 1961 to 2018 Oecd (2021). These are income elastic foods and once the socio-economic conditions improved in the country, the meat consumption also rose. According to Devi et al. (2014), meat demand is associated with higher incomes and a shift due to urbanization.

It can be inferred from the results of the present study, that when meat production was low in India, fish and dry fish were the main source of non -vegetarian foods to the population. There was high demand and popularity for dry fish, especially in rural areas and small towns, before the beginning of urbanization. Urbanization and rising incomes have altered the food preferences as also reported in a review paper on meat consumption Devi et al. (2014). It is understood that the availability of the cooling gadgets like refrigerator is one of the influencing factors of food consumption. During the years 1960's, 1970's etc., the cooling gadgets were almost negligible in majority of Indian households and an increasing market is seen in this decade, especially in urban areas, according to a report on refrigerators market in India Https://WWW .Mordorintelligence.Com/Industry-Reports/India-Refrigerator-Market (2021). So, it can be assumed that when food storage was a challenge, dried fish was extensively used. Whenever fresh fish was not available or not affordable, dry fish served as a ready resource at home and was handy for the meal planning. Hence, it was in great demand as part of daily diet, in earlier days or precisely before the urbanization period.

\section{CONCLUSIONS AND RECOMMENDATIONS}

The study on dry fish consumption indicates that dry fish is preferred by adolescents of Andhra Pradesh. However, an access to diversified foods, improved socioeconomic conditions, modernisation and access to refrigerators by common man, has impacted the patronage for dry fish, making it a less preferred food commodity in comparison to other non -vegetarian foods like meat, chicken and eggs. On an average, about $60 \%$ of the respondents in the present study did not eat dry fish while those who liked eating, showed a preference for monthly consumption. The trends were similar in rural and urban areas of Andhra Pradesh. There are very few studies on consumption of dry fish in India and no periodic data trends are available in literature.

\section{REFERENCES}

Anand, S. N. (2020). Dried Fish Is A Much-Loved Alternative To Fresh Fish Across The Country, The Hindu (Newspaper) Category - Food, August 25., 58-58.

Assocham. (2016). Retrieved from Https://Economictimes.Indiatimes.Com/News/ Economy/Foreign-Trade/New-Packing-Technology-To-Increase-Export-Of-Dry -Fish/Articleshow/50837968.Cms

Das, M., Rohit, P., Maheswarudu, G., Dash, B., \& Ramana, P. V. (2013). Overview Of Dry Fish 
Landings And Trade At Visakhapatnam Fishing Harbour. Marine Fisheries Information Service T\&E Ser(215), 3-7.

Devi, M., Subramaniam, Balachandar, Vellingiri, Lee, \& Kim, S. . (2014). In Ho. An Outline Of Meat Consumption In The Indian Population - A Pilot Review.Korean Journal For Food Science Of Animal Resources., 34, 507-515. 10.5851/Kosfa.2014.34.4.507

Immaculate, K., Sinduja, P., Velammal, A., \& Patterson, J. (2013). Quality And Shelf Life Status Of Salted And Sun Dried Fishes Of Tuticorin Fishing Villages In Different Seasons. Int. Food Res. J, 20(4), 1855-1859.

The Indian History, From Stone Age To Modern India. (2021). Retrieved from Http:// Theindianhistory.Org/Ancient-Indian-Food.Html

Madhavi, D., \& Kusuma, D. L. (2015). Fish Consumption Pattern And Its Association With Household Characteristics In Select Coastal And Non -Coastal Districts Of Andhra Pradesh. International Journal of Science And Research (Ijsr) Issn, 4(5), 2472-2478.

Manay, N. S., \& Swamy, M. S. (2021). Seafoods, Chap.25, Foods- Facts And Principles. New Age International (P), Limted, Publishers, New Delhi, 411-419.

Nayak, B. (2021). Is Dry Fish Good Or Bad For Health? Food Blog, January,13. 2021. Retrieved from Https://Www.Drbrahma.Com \char"203A \relaxIs-Dry-Fish-Good-Or-Bad-F...

Nummer, B. A. (2002). Historical Origins Of Food Preservation, National Center For Home Food Preservation, May 2002 Accessed At . (Reprinted With Permission Of The University Of Georgia. B.A. Nummer. 2002. Historical Origins Of Food Preservation. Athens, Ga: The University Of Georgia, National Center For Home Food Processing And Preservation). Retrieved from Https://Nchfp.Uga.Edu/Publications/Nchfp/Factsheets/Food _Pres_Hist.Html,On28/7/2021

Oecd. (2021). Meat Consumption (Indicator). 10.1787/Fa290fd0-En

Sajeev, M. V., Mohanty, A. K., Sajesh, V. K., \& Rejula, K. (2020). Dried Fish Consumption Patterns In Selected Districts Of Kerala. Fishtech Rep, 6(2), 14-16.

Shashikanth, M., H, \& Somashekar, D. (2020). Survey Of Fish Consumption Pattern In Households Of Shivamogga. Karnataka, Global Journal Of Zoology.

Siddhnath, A., Ranjan, Mohanty, P. B. P., \& Saklani. (2020). Krushna Chandra Dora \& Supratim Chowdhury. Dry Fish And Its Contribution Towards Food And Nutritional Security. Food Reviews International.

Singh, K. (2020). In Veg-Friendly India, Meat Consumption Is On The Rise, Sentient Media, Culture-August 24.

Singh, S. (2017). A Fishing Holiday For Marine Health, India Water Portal, 15-9-2017., 15-24. Retrieved from Https://Www.Indiawaterportal.Org/Articles/Fishing-Holiday-Nature -WorkOn24/7/2021.

(2021). Retrieved from Https://Www.Mordorintelligence.Com/Industry-Reports/ India-Refrigerator-Market

Wilson, C. A. (1991). Preserving Food To Preserve Life: The Response To Glut And Famine From Early Times To The End Of The Middle Ages In "Waste Not, Want Not": Food Preservation From Early Times To The Present, C. Anne Wilson. Ed. Edinburgh: Edinburgh Univ.1991-Accessed At. Retrieved from Http://Lynettehunteronline.Com/Wp -Content/Uploads/2014/04/1989-Food-Preserving.Pdf,On28/7/2021 